\title{
INTRAMEDULARY EPIDERMOID CYST OF THE DORSAL SPINE: A CASE
} REPORT.

\author{
Dr. Md. Shafiul Alam ${ }^{1 *}$, Dr. Tayseer Farzana ${ }^{2}$ \\ ${ }^{*}$ Associate Professor, Department of Gamma Knife Neurosurgery, National Institute of Neurosciences, Bangladesh. \\ Email:dr_chapal@hotmail.com \\ ${ }^{2}$ Consultant, Department of Radiology and Imaging, Papular Diagnostic Center, Mirpur Branch, Dhaka. Email: \\ tayseercpl@yahoo.com \\ The name of the department and institution to which the work should be attributed: \\ Department of Neurosurgery, National Institute of Neurosciences, Dhaka, Bangladesh.
}

*Corresponding author:

Email: dr_chapal@hotmail.com, Mobileno.01711567358

\begin{abstract}
: -
Spinal epidermoid cysts are cystic tumours lined by squamous epithelium. Unlike dermoid cysts, they do not contain skin appendages (hair follicles, sweat glands, sebaceous glands). They are usually extramedullary but rarely can be intramedullary. They may be congenital or acquired. Especially they are not associated with spinal dysraphism. Intramedullary epidermoid cysts of the spinal cord are rare tumours, only few cases having been reported in the literature. They comprise between $0.5 \%$ to $1 \%$ of all spinal tumours but account for up to $10 \%$ of intraspinal tumours in children. We report a case of 45 years-old female patient who presented with a 18 months history of progressive lower extremity weakness and spasticity. But her bowel/bladder function was normal. Magnetic resonance imaging of the thoracic spine revealed a $3 \mathrm{~cm}$ intramedullary mass at the T3-4 level. A T3 to T5 laminnectomy with complete removal of the intradural mass was performed. Intraoperative findings and final histopathological examination revealed an epidermoid cyst.Total excision of the tumor was performed. The patient showed progressive recovery.
\end{abstract}

Key words: Epidermoid cyst, Dorsal spine, Intramedulary

\section{(c) $(\$)$}




\section{INTRODUCTION}

An epidermoid cyst is a slow growing indolent rare lesion.[2] Most of the spinal epidermoid cysts are subdural and extramedullary. Intramedullary localization is very rare with $<60$ cases reported so far since the first reporting by Chiari (1833), and very few cases can be diagnosed preoperatively by magnetic resonance imaging (MRI) characteristics. $[2,3,4,5,6,7]$ Most common location is dorsal followed by lumbosacral region. [6,8] Although microsurgical total excision is the treatment of choice, it is often not possible due to adherence to cord.

\section{Case report}

A 45 years-old female patient presented to us with history of gradual weakness of both lower limbs for 18 months. The weakness continued to progress and fnally it was difficult to walk for her. But there was no history of bowel/ bladder disturbances. Neurological examination revealed increased muscular tone; wasting of both lower limbs muscle; power $3 / 5$ in all muscle groups of both lower limbs. Ankle and knee jerks were exaggerated in both sides with extensor plantar response. Upper limbs were normal. Her general and other systemic examination was normal. MRI dorsal spine revealed a well-defined intramedullary lesion about $3 \mathrm{~cm}$ in vertical diameter at the level of T3-T4, expanding the cord. The lesion was hypointense on T1 WI and T2 WI suggestive of cyst without perilesional edema. It showed mild enhancement after contrast administration. [Figure 1]. The patient underwent T3 to T5 laminectomy. [Figure 2]. The dura was opened and a posterior mid line myelotomy was performed followed by a total excision of the cyst and duroplasty was done. Intraoperatively, there were white flaky fragments suggestive of epidermoid lesion. On histopathology the lesion had a thin fibrous capsule, encircled by gliotic tissue. Cyst was lined by compressed stratified squamous epithelium and contained degenerated squamous tissue [Figure 3]. All these features were characteristic of intramedullary epidermoid. The patient showed progressive recovery after surgery.

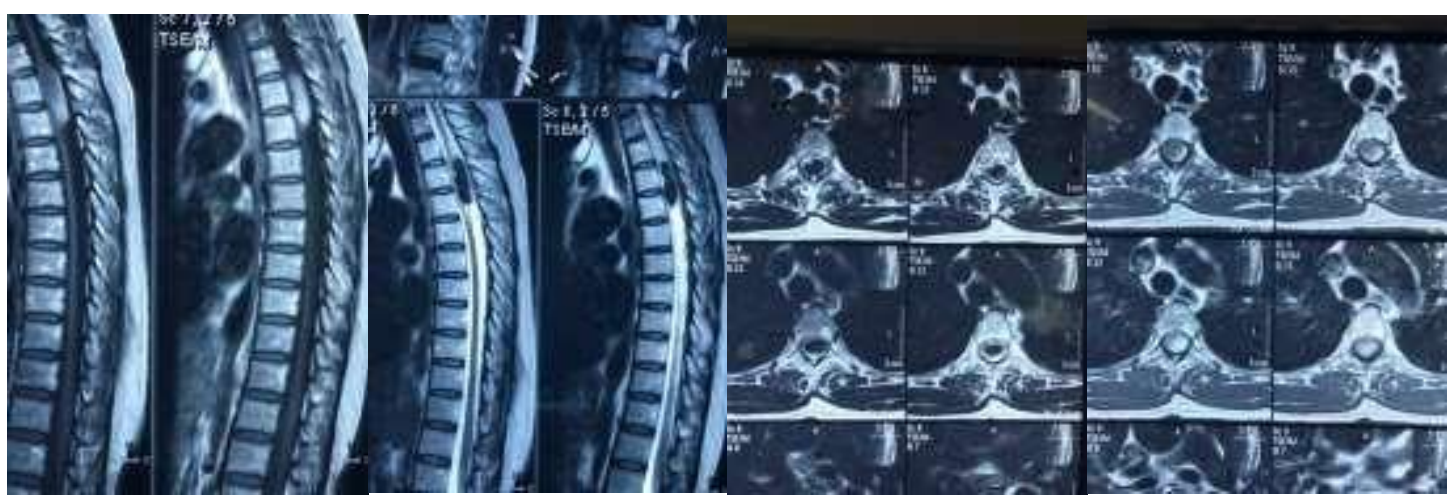

Figure 1: Pre operative MRI Scan

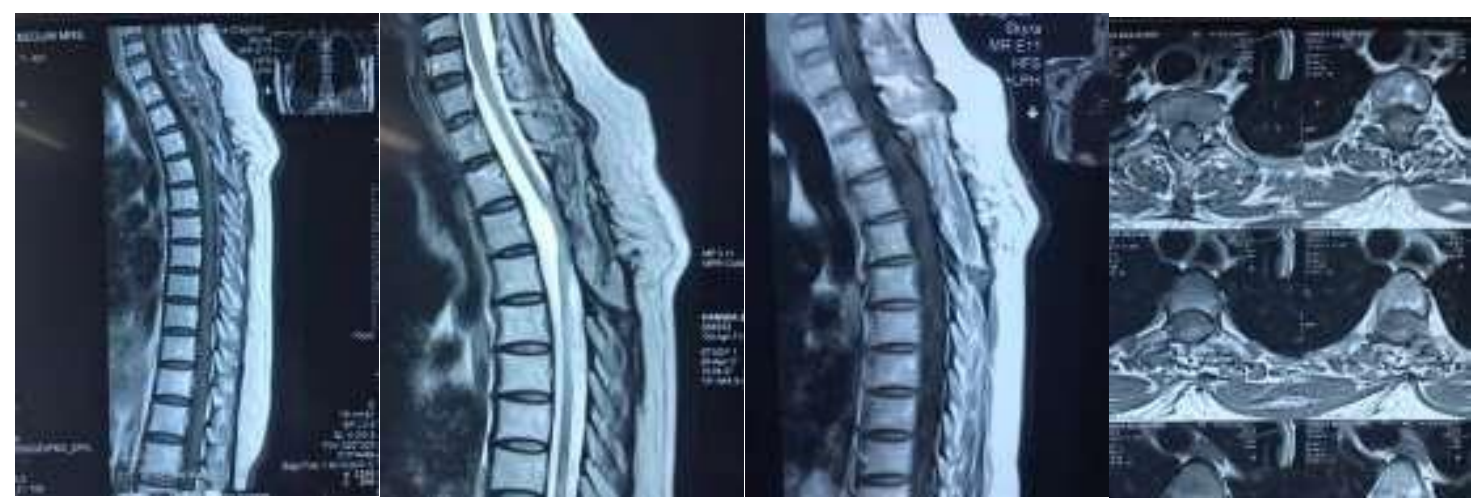

Figure 2: Post operative MRI Scan

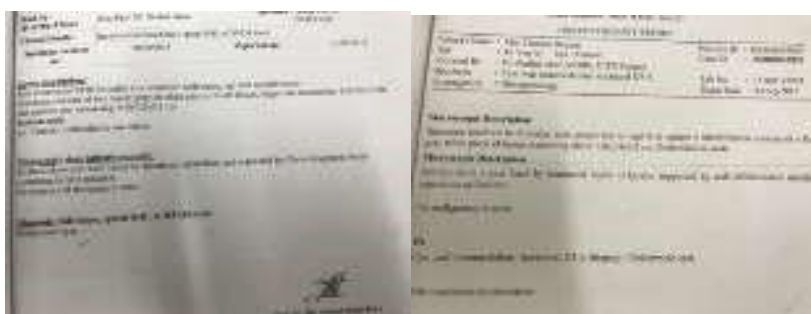

Figure 3: Histopathology report

\section{Discussion}

Spinal epidermoid cyst is either congenital or acquired. Most of spinal epidermoid cysts are congenital because of displacement of ectodermal inclusions during the closure of neural tube. Congenital epidermoid cyst can be associated with other abnormalities, e.g., hemivertebra, dermal sinus, spina bifida, syringomyelia, but may occur in isolation also. 
Defect of the overlying bone reported in about $10 \%$, is possible but less frequent than in dermoid or some extramedullary epidermoids.[2,4,9,10] Isolated spinal epidermoid may present with either progressive compressive myelopathy, as in our case, or acute onset chemical meningitis (rupture of cyst and spread of cholesterol crystals into cerebral spinal fluid). Acquired epidermoid cyst, due to iatrogenic penetration of skin fragments, have been reported after lumbar puncture or meningomyelocele repair with a latency of years together. [3,7,14,15]

Clinical presentation is usually neurological, but rarely there may be urological involvement.[8] Diagnosis, often based on intraoperative and histological findings. Computed tomography scan of an epidermoid cyst is characterized by a lowdensity lesion that does not enhance. $[6,7,11,12]$ MRI findings may be quite divergent, because of the disparity of signal intensity secondary to various lipid and protein composition. Amato et al. stated, in patients with spinal dysraphism MRI findings of well-defined, heterogeneous, T1-weighted hypointense lesion without perilesional edema may suggest tumor of developmental origin, e.g., epidermoid cyst, teratoma, or dermoid cyst. In absence of associated dysraphisms, diagnosis might be made by careful and complete MRI study including diffusion weighted imaging (DWI) sequences. [1,10,16] MRI characteristics of variable signal intensity between different parts of the same cyst at times, absence of perilesional edema, fairly well-defined limits, and peripheral postgadolinium enhancement favors the diagnosis of epidermoid cyst. Margins of the epidermoid cyst may occasionally be "shaggy" because of chronic inflammatory response to squamous tissue "leak" through capsule and variable gliosis along the margin extending into the cord. These features help in differentiating from other intramedullary tumors, e.g., dermoid cyst, ependymoma, astrocytoma, teratoma, and hemangioma. [1,4,7] Some authors believe the peripheral enhancement represents normal tissue reaction surrounding tumor, while others consider it as outer tumor wall composed of tumor cells. [2,7] We believe it may be due to normal tissue reaction.

The surgical goal is complete excision. Sometimes, capsule is very thin and tightly adherent to the cord or located within its confines, warranting safe maximal resection to avoid damage to cord. Most authors believe in not attempting total removal of capsule in such cases. In most cases, even partial removal resulted in total remission of symptoms. [7,11,12,13] Adherence of capsule to cord anteromedially. Operative complications may include damage to the neurovascular structures, and sphincter disturbances. Aseptic chemical meningitis, unique to epidermoid lasting for weeks, if severe and long-lasting can lead to a "granulomatous" type of arachnoiditis.[13] Plugging of proximal and distal arachnoid space prior to tumor resection and irrigating and washing the site with normal saline prior to dural closure diminishes the chances of spillage of epidermoid and reduces the chances of chemical meningitis.

Histopathologically, epidermoid cysts are lined by stratified squamous epithelium supported by an outer layer of collagenous tissue; presence of skin adnexa dictates the diagnosis of dermoid. In epidermoid cyst, progressive desquamation of keratin from epithelial lining toward the interior of cyst produces a soft cheesy white material with histopathology revealing desquamated epithelium surrounded by keratin-producing squamous epithelium. [3,7,11,12,14] The risk of recurrence does exist and depends upon the degree of resection. Gross total removal along with the capsule diminishes the chances of recurrence. Though, radiotherapy has been mentioned as the treatment modality for only one case in the literature, symptomatic recurrences are best treated by surgery. [5,17]

\section{Conclusion}

Spinal Intramedullary epidermoid cysts are rare tumors without any specific clinical presentation. Clinical presentation is usually neurological. Diagnosis is often based on intraoperative and histopathological findings, but possible early on complete MRI profile including DWI sequences. Complete microsurgical excision is the treatment of choice, and results in cessation of clinical progression and remission of symptoms sometimes limited by adherence of cyst to cord or its confines. Maximal safe resection in those cases reduces the morbidity and helps the patients with good long term functional outcome in these slow growing benign conditions.

\section{References}

[1].Scholz M, Märzheuser-Brands S, Gottschalk J, Böck JC, Lanksch WR. Intramedullary epidermoid cyst. A case report. Neurosurg Rev. 1994;17:89-93. [PubMed]

[2].Penisson-Besnier I, Guy G, Gandon Y. Intramedullary epidermoid cyst evaluated by computed tomographic scan and magnetic resonance imaging: Case report. Neurosurg. 1989;25:955-9. [PubMed]

[3].Bansal S, Suri A, Borkar SA, Kale SS, Singh M, Mahapatra AK. Management of intramedullary tumors in children: Analysis of 82 operated cases. Childs Nerv Syst. 2012;28:2063-9. [PubMed]

[4].Roux A, Mercier C, Larbrisseau A, Dube LJ, Dupuis C, Del Carpio R. Intramedullary epidermoid cysts of the spinal cord. Case report. J Neurosurg. 1992;76:528-33. [PubMed]

[5].Kumar A, Singh P, Jain P, Badole CM. Intramedullary spinal epidermoid cyst of the cervicodorsal region: A rare entity. J Pediatr Neurosci. 2010;5:49-51. [PMC free article] [PubMed]

[6].Cincu R, Lázaro JF, Liesa JL, Callizo JR. Dorsal intramedullary spinal epidermoid cysts: Report of two cases and review of literature. Indian J Orthop. 2007;41:395-7. [PMC free article] [PubMed]

[7].Chandra PS, Manjari T, Devi BI, Chandramouli BA, Srikanth SG, Shankar SK. Intramedullary spinal epidermoid cyst. Neurol India. 2000;48:75-7. [PubMed]

[8].Ferrara P, Costa S, Rigante D, Mule A, D’Aleo C, Pulitanò S, et al. Intramedullary epidermoid cyst presenting with abnormal urological manifestations. Spinal Cord. 2003;41:645-8. [PubMed]

[9].Kirsch WM, Hodges FJ., 3rd An intramedullary epidermal inclusion cyst of the thoracic cord associated with a previously repaired meningocele. Case report. J Neurosurg. 1966;24:1018-20. [PubMed] 
[10]. Gupta S, Gupta RK, Gujral RB, Mittal P, Kuriyal M, Krishnani N. Signal intensity patterns in intraspinal dermoids and epidermoids on MR imaging. Clin Radiol. 1993;48:405-13. [PubMed]

[11]. Kaye AH. Essential Neurosurgery. USA: Churchill Livingstone; 1991. pp. 144-6.

[12]. Findlay GF. Compressive and vascular disorders of the spinal cord. In: Miller JD, editor. Northfield's Surgery of the Central Nervous System. 2nd ed. UK: Blackwell Scientific Publications; 1987. pp. 739-40.

[13]. Conley FK. Epidermoid and dermoid tumors: Clinical features and surgical management. In: Wilkins RH, Rengachary SS, editors. Neurosurgery. I. USA: McGraw-Hill Book Company; 1985. pp. 668-73.

[14]. Manno NJ, Uihlein A, Kernohan JW. Intraspinal epidermoids. J Neurosurg. 1962;19:754-65. [PubMed]

[15]. Halcrow SJ, Crawford PJ, Craft AW. Epidermoid spinal cord tumour after lumbar puncture. Arch Dis Child. 1985;60:978-9. [PMC free article] [PubMed]

[16]. Amato VG, Assietti R, Arienta C. Intramedullary epidermoid cyst: Preoperative diagnosis and surgical management after MRI introduction. Case report and updating of the literature. J Neurosurg Sci. 2002;46:122-6. [PubMed]

[17]. Bretz A, Van den Berge D, Storme G. Intraspinal epidermoid cyst successfully treated with radiotherapy: Case report. Neurosurgery. 2003;53:1429-31. [PubMed] 